\title{
Design, Construction, and Evaluation of the Performance of Dual-Axis Sun Trucker Parabolic Solar Cooker and Comparison of Cooker
}

\author{
Solomon Tibebu $\mathbb{D D}^{1,2,3,4}$ and Arkbom Hailu $\mathbb{D D}^{1,2}$ \\ ${ }^{1}$ Department of Environmental Engineering, College of Biological and Chemical Engineering, \\ Addis Ababa Science and Technology University, Addis Ababa, Ethiopia \\ ${ }^{2}$ Sustanable Energy Center of Excellence, Addis Ababa Science and Technology University, Addis Ababa, Ethiopia \\ ${ }^{3}$ Bioprocess and Biotechnology Center of Excellence, Addis Ababa Science and Technology University, Addis Ababa, Ethiopia \\ ${ }^{4}$ Environmental Protection and Green Development Commission, Addis Ababa, Ethiopia \\ Correspondence should be addressed to Solomon Tibebu; solomon.tibebu@aastu.edu.et
}

Received 6 July 2021; Revised 2 August 2021; Accepted 16 August 2021; Published 7 September 2021

Academic Editor: Pallav Purohit

Copyright (C) 2021 Solomon Tibebu and Arkbom Hailu. This is an open access article distributed under the Creative Commons Attribution License, which permits unrestricted use, distribution, and reproduction in any medium, provided the original work is properly cited.

\begin{abstract}
Energy demand is increasing due to population increment and industrialization. To meet this energy demand, technologies that use renewable energy such as solar energy are being developed. A parabolic solar cooker is one of the main solar cookers, which can cook food and boil water at a high temperature within a short period. This study aimed to design, construct, and evaluate the performance of the constructed parabolic solar cookers. Moreover, this study aimed to compare the constructed cooker with firewood, charcoal, kerosene, and electricity in terms of cooking time and energy cost. The cooker was constructed using different materials such as old satellite dishes, tyres, steel, and aluminum foil. The aperture diameter, aperture area, receiver diameter, receiver area, depth of the parabola, focal length, rim angle, circumference of the circle, surface area, length of the circumference, and concentration of the cooker were $1.8 \mathrm{~m}, 2.54 \mathrm{~m}^{2}, 0.16 \mathrm{~m}, 0.02 \mathrm{~m}^{2}, 0.3 \mathrm{~m}$, $0.67 \mathrm{~m}, 67.38^{\circ}, 5.76 \mathrm{~m}, 2.81 \mathrm{~m}^{2}, 5.76 \mathrm{~m}$, and 123.46 , respectively. The cooker can track the sun from north to south and from east to west. The performance of the cooker was evaluated by calculating the efficiency and power. The output energy, input energy, and average upcoming solar radiation of the constructed parabolic solar cooker were $0.182 \mathrm{~kW} / \mathrm{m}^{2}, 1.691 \mathrm{~kW} / \mathrm{m}^{2}$, and $0.665 \mathrm{~kW} / \mathrm{m}^{2}$, respectively. The efficiency and power of the cooker were $10.75 \%$ and $0.3 \mathrm{~kW} / \mathrm{hr}$, respectively. The constructed parabolic solar cooker relatively showed better performance in cooking different foods. A family, which has five members, was considered to compare the constructed cooker with other fuels in terms of energy cost of cooking. Since the parabolic solar cooker does not have any energy cost, it can save the energy cost of cooking foods. Therefore, parabolic solar cookers have a great advantage for developing countries including Ethiopia.
\end{abstract}

\section{Introduction}

Energy is one of the necessities to live on this planet $[1,2]$. Plants use energy to prepare their food, humans use energy to cook their food, and industries use energy to manufacture different products [3]. In early times, energy is completely harnessed from fossil fuels (coal, oil, and natural gas). As humans become more civilized, their industries also grow, which in turn increased energy demand. The rapid increment in population also contributed to the increment of 
energy demand [4-6]. This caused an increment in the utilization of fossil fuels. Eventually, this started to degrade the environmental quality [7]. Global warming, which is caused by the increase in the concentration of greenhouse gases in the atmosphere due to the burning of fossil fuels, causes the increment of the earth's mean temperature $[8,9]$. This in turn causes climate change, which is responsible for different hazards such as floods and drought [10]. The burning of fossil fuels also causes acid rain, which can cause an adverse impact on forests, freshwater, and soil [11]. The fluctuation and increment of fossil fuel prices were also the other problems that affected countries, whose economy depends on nonrenewable energy [12]. Moreover, according to Hafner and Tagliapietra [13], after a few hundred years, all fossil fuels in sub-Saharan African countries will be extracted.

To solve the above problem, in addition to energy conservation, researchers started to study more about alternative energy resources such as solar, wind, hydro, geothermal, tidal, and biomass, which are commonly called renewable energy [14-17]. These energy sources are clean and environmentally friendly. Green energy (renewable energy) plays an important role to have affordable, accessible, and reliable energy for all [18]. Renewable energy diversifies the energy source and reduces the utilization of fossil fuels $[19,20]$. Unlike solar energy, most renewable energy sources require high technological advancement for installation and operation [21]. Therefore, solar energy is a preferable energy source for developing countries including Ethiopia [22-24].

Solar energy has the potential to become the primary energy source in all Africa countries [25]. This is mainly due to the high solar intensity reaching the earth's surface [26]. Also, these countries get solar energy for a longer period throughout the year [27]. According to Griffiths [28], most of the continent enjoys sunshine for a longer season per year. Due to the spherical shape of the earth, the surface of the earth will not get uniform solar radiation [29]. Countries such as Ethiopia, which are located near the equator, can get a bigger advantage from this energy source because of the high solar intensity. According to Khadem et al. [30], the annual average daily radiation on a horizontal surface in Ethiopia is $3.74 \mathrm{kWh} / \mathrm{m}^{2}$ with a minimum of 1.5 and a maximum of $4.9 \mathrm{kWh} / \mathrm{m}^{2}$. We can use solar energy for different purposes such as generating electricity, boiling water, and cooking food [31].

Nearly 730 million people in sub-Saharan Africa countries rely on biomass as a primary energy resource [32]. Among the different types of biomass, most African countries utilize firewood, which indicates that deforestation is a big problem in this continent [21]. In Ethiopian rural areas, firewood is the main source of energy, but in cities, electricity, kerosene, and charcoal are the main sources [33].

In Ethiopia, over $80 \%$ of the population utilizes biomass as a primary source of energy [34]. According to Overend [35], the main reason for the consumption of biomass in sub-Saharan countries is for cooking purposes. In most developing countries, there is a shortage of firewood due to the high consumption of energy and cooking in an inefficient stove in a poorly ventilated space [36]. Cooking food requires firewood gathering and frequent attention to make sure the food cooks evenly. Moreover, when women and children collect firewood for cooking and other purposes, they may face sexual harassment such as rape, unwanted pregnancy, psychological problem, and sexually transmitted diseases [37]. Utilizing charcoal in poorly ventilated spaces can cause a serious respiratory problem due to the emission of carbon monoxide and other gases [38]. Kerosene is expensive; therefore, it is not usually utilized in rural areas [39]. Electricity is cheap, but it has low coverage in rural areas of most developing countries [40].

\section{Literature Review}

A solar cooker is a device that uses the sun's energy to cook food [15, 41]. Solar cookers can eliminate the problems that come with utilizing firewood, charcoal, kerosene, and electricity. Unlike firewood, charcoal, and kerosene, solar cookers do not emit harmful gases that can cause air pollution and global warming [31]. Fire accidents will not be a problem in cooking with solar cookers. No trees have to be cut for firewood, which in turn helps to prevent soil erosion [42]. Unlike kerosene, since they use only the sun's energy, they are not expensive. Unlike electricity, they can cover all parts of rural areas without spending a big budget. Box, parabolic, and panel cookers are the three main types of solar cookers [43]. Solar cookers use solar radiation either by reflecting the radiation to concentrate on a cooking pot or by retaining the radiation to trap the heat [44].

A parabolic solar cooker is one of the main solar cookers, which can cook food and boil water at a high temperature within a short period [2, 45, 46]. According to Mbodji and Hajji [47], parabolic solar cookers can be designed and manufactured for thermal applications. In a parabolic solar cooker, the reflecting material, which is shaped in a parabola, receives the sun radiation and reflects it to the bottom of the cooking pot. This causes the heating effect, which will be used to cook different foods [44, 48, 49]. A parabolic solar cooker requires a frequent adjustment of the cooker towards the sun [2].

Arenas experimented on a parabolic solar cooker and discovered that this cooker can achieve an average power scale of $175 \mathrm{~W}$ and an efficiency of $26.6 \%$ [50]. Al-Soud et al. designed and constructed a two-axis automatic sun trucker parabolic solar cooker and experimented in 2008 for three days. During the experiment, the water temperature had reached $90^{\circ} \mathrm{C}$ at an ambient temperature of $36^{\circ} \mathrm{C}$ [46]. Suple and Thombre experimented on a parabolic solar disc that can be operated from the kitchen through biaxial manual tracking [51]. Lee and Rao constructed the three main types of solar cooker and discovered that the parabolic solar cooker achieved the highest temperature at $86.5^{\circ} \mathrm{C}$. Moreover, different technologies regarding parabolic solar cookers are being developed throughout the world [52-55].

As far as the knowledge of the authors is concerned, only a few researches have been conducted regarding the performance of parabolic solar cookers in Ethiopia [55, 56]. Moreover, in 
Ethiopia, a comparison of the parabolic solar cooker with other fuels in terms of cooking time and energy cost has not yet been investigated. Therefore, this study aimed to design, construct, and evaluate the performance of parabolic solar cookers and compare the cooker with firewood, charcoal, kerosene, and electricity in terms of cooking time and energy cost of cooking.

\section{Materials and Methods}

3.1. Description of the Study Area. The experiment was conducted in a site, which is located in Addis Ketema subcity, Addis Ababa, Ethiopia. The site is located at $90^{\circ}$ $02^{\prime} 59^{\prime \prime}$ and $38^{\circ} 43^{\prime} 54^{\prime \prime}$ and has an altitude of $2459 \mathrm{~m}$. According to the data that is collected from the Ethiopian metrological agency, Addis Ketema has an average temperature, rainfall, and relative humidity of $15.9^{\circ} \mathrm{C}, 1089 \mathrm{~mm}$, and $60.7 \%$, respectively. Figure 1 shows a map of the study area.

\subsection{Experimental Design and Operation of Parabolic Solar} Cooker. To construct a parabolic solar cooker, one old satellite dish with its base, four small tyers, steel $(\varnothing=25 \mathrm{~mm})$, adhesive, aluminum foil, and a small pot were used. The old dish was first washed with tap water to remove the dirt and dried using a clean towel. Then the surface of the dish was covered with aluminum foil with the help of adhesive. Four small tyers were welded on the stand base so that the cooker can track the sun from east to west. The stand base can also track the sun from north to south because of its capacity to stretch from $72 \mathrm{~cm}$ to $108 \mathrm{~cm}$. This particular future makes the cooker have a dual-axis tracking capacity that can track the sun east to west daily and north to south seasonally. Figure 2 shows the different components of the cooker.

The schematic diagram of the parabolic solar cooker is shown in Figure 3.

The aperture area, receiver area, focal length, rim angle, arc length of the paraboloid, surface area of a paraboloid, length of the circumference, and concentration ratio of the parabolic solar cooker were designed based on the formulas that are listed in Table 1.

By using the calculated focal length, steel support was constructed and welded on the stand base. By considering the diameter of the pot, a receiver, which is used to suspend the pot and keep it on the focal point, was constructed and welded on the support steel. As shown in Figure 4, the bottom part $(\varnothing=16.00 \mathrm{~cm})$ of the pot can pass through the ring-shaped receiver $(\varnothing=16.22 \mathrm{~cm})$, but the upper part of the pot $(\varnothing=16.44 \mathrm{~cm})$ could not pass through the ring.

The pot was painted black because of the high absorption of light and the low reflective property of the color. The depth of the parabola $(d)$ and circumference of the circle $(C)$ were $0.3 \mathrm{~m}$ and $5.76 \mathrm{~m}$, respectively. Finally, all components of the cooker were assembled as shown in Figure 5.

3.3. Performance Evaluation of the Cooker. The generated data were analyzed by Microsoft Excel 2013. The performance of the cooker was evaluated using the following formulas:

$$
\begin{aligned}
\text { Q out put } & =(m 1 * C p * \Delta T)+(L * m 2), \\
S & =\frac{\text { solar radaiation data }}{\text { number of data }}, \\
\text { Q input } & =\left(A\left(\mathrm{~m}^{2}\right)\right) *\left(S\left(\frac{\mathrm{kW}}{\mathrm{m}^{2}}\right)\right), \\
\eta & =\left(\frac{\text { Q output }}{Q \text { input }}\right) * 100 \%, \\
P & =\frac{Q \text { out }(\mathrm{kW})}{\text { time }(\mathrm{h})},
\end{aligned}
$$

where $\eta$ denotes efficiency, $Q$ input denotes heat energy input (kJ), $Q$ output denotes heat energy output $(\mathrm{kJ}), m 1$ denotes the mass of water before boiling ( $\mathrm{g}), \mathrm{m} 2$ denotes the mass of water after water (g), Cp denotes specific heat capacity of water, $\Delta T$ denotes a change in temperature, $L$ denotes latent heat of vaporization of water, $A$ denotes aperture area of the paraboloid, $S$ denotes average upcoming solar radiation, $P$ denotes power, and $h$ denotes the hour.

$\mathrm{Q}$ output is determined by boiling one liter of water using a parabolic solar cooker for 36 minutes. The $\mathrm{Cp}$ and $L$ of water are $4.186 \mathrm{~J} / \mathrm{g}{ }^{\circ} \mathrm{C}$ and $2260 \mathrm{~kJ} / \mathrm{kg}$, respectively. The metrological data was used to determine the upcoming solar radiation $(S)$, which in turn helps to determine $Q$ input. The solar radiation data was collected from the Ethiopian metrological stations. Table 2 shows the metrological data of the experimental site during boiling $1 \mathrm{~L}$ water. This data was collected from the Ethiopian metrological agency.where $A$ denotes the energy cost of cooking/boiling for a family, $B$ denotes the energy cost of cooking/boiling for a single person, $C$ denotes the consumption of food for one family, which have five members, $E$ denotes the amount of fuel used to cook foods and boil water, and $F$ denotes the cost of fuel in $\mathrm{kg}$ for charcoal and firewood, litter for kerosene, and $\mathrm{kW}$ for electricity.

$$
\begin{aligned}
& A=B * C, \\
& B=E * F,
\end{aligned}
$$

\subsection{Quantity of Fuels and Foods Used for Comparison Purpose.} Table 3 summarizes the amount of fuels used to cook different foods and boil water so that they could be compared with the constructed parabolic solar cooker in terms of cooking time and energy cost of cooking.

Table 4 summarizes the quantity of foods that are cooked by the parabolic solar cooker and the cooking time interval. In cooking different foods and boiling water, the parabolic solar cooker was adjusted by rotating it from north to south and east to west so that a high amount of solar radiation can be received and reflected to the concentrator. The adjustment was conducted by considering the hour of the day and season. The same type and quantity of foods are cooked using charcoal, firewood, kerosene, and electricity for comparing the parabolic cooker with these fuels. In addition, for this study, the average consumption 


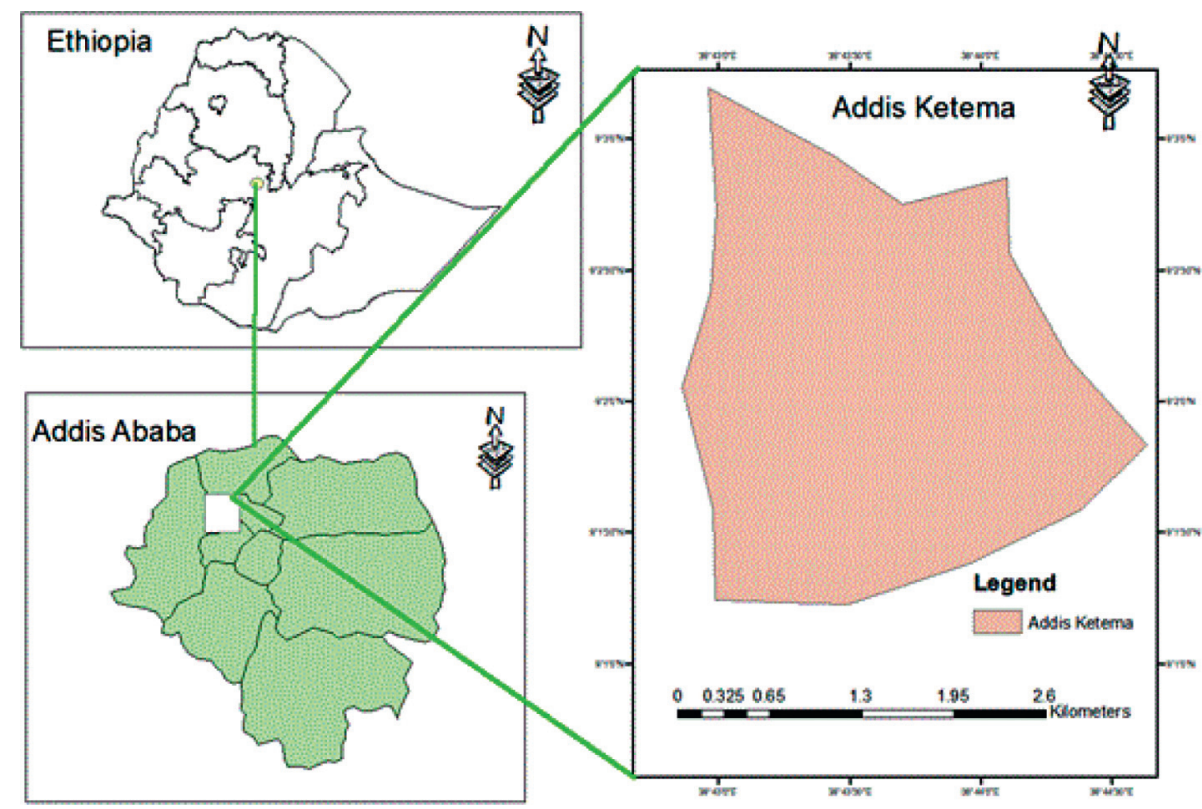

Figure 1: Map of the study area.

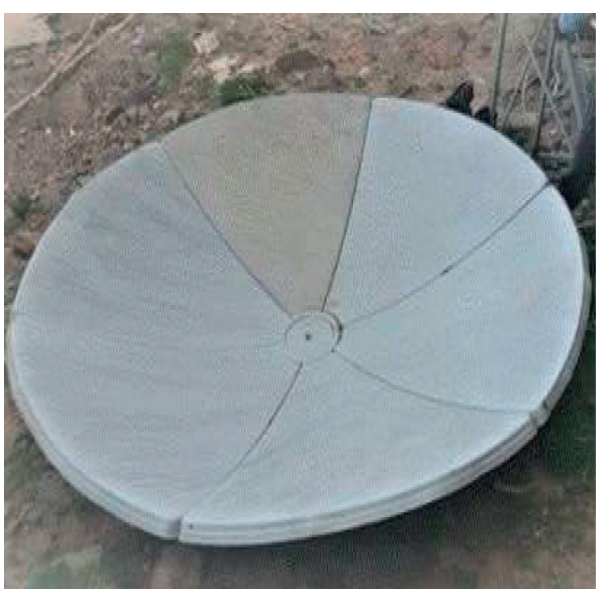

(a)

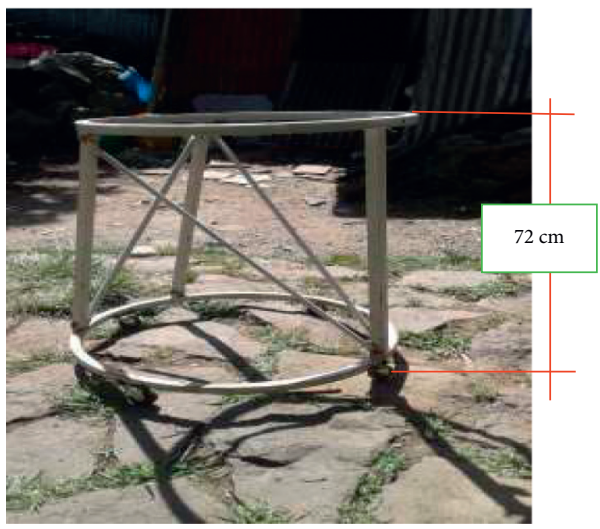

(c)

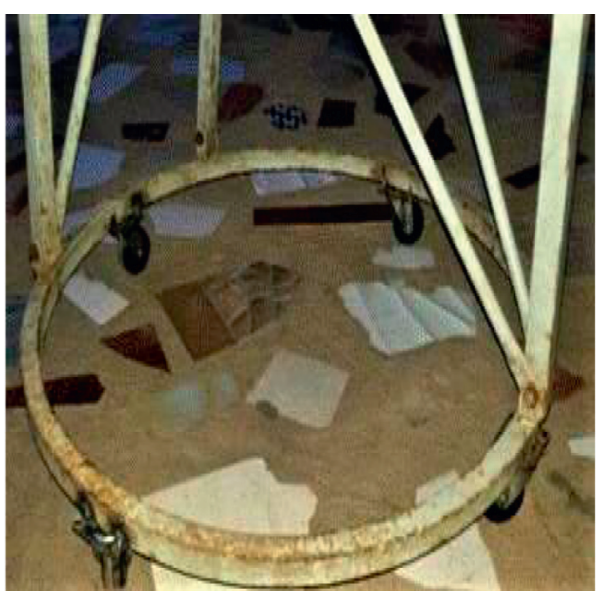

(b)

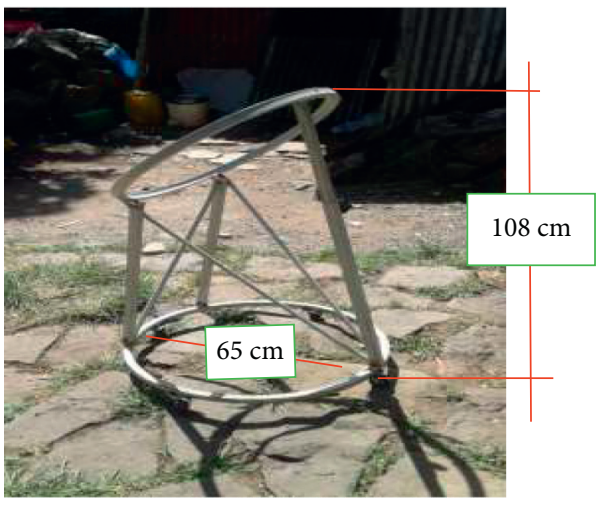

(d)

Figure 2: Old dish (a), welded tyers (b), and stand base (c, d). 


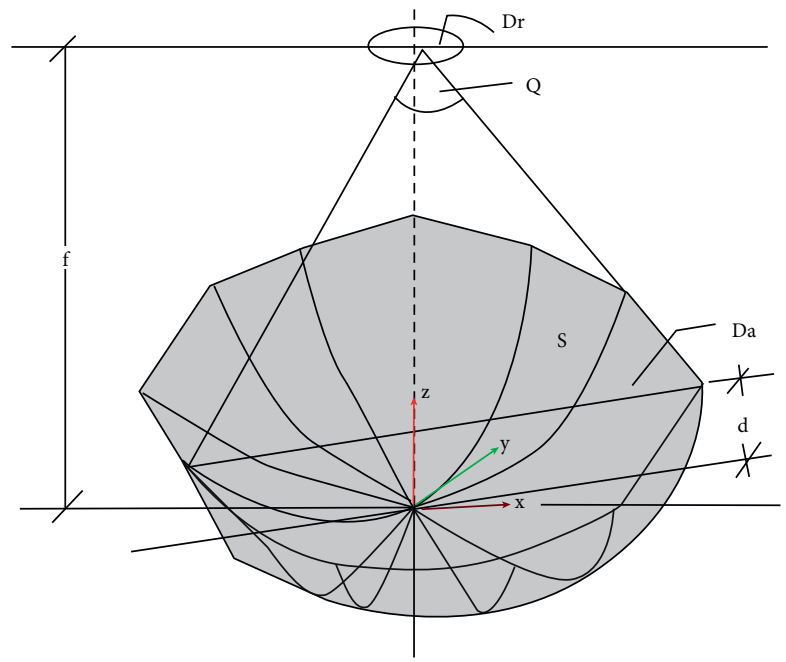

Figure 3: Design of parabolic solar cooker, where $D a$ denotes aperture diameter, $D r$ denotes receiver diameter, $S$ denotes arc length of the paraboloid, $F$ denotes focal length, $Q$ denotes rim angle, and $d$ denotes the vertical length of the curvature.

TABle 1: Design formulas of parabolic solar cooker.

\begin{tabular}{lccc}
\hline No. & Parameter & Equations & Equation number \\
\hline 1 & Aperture area $(A a)$ & $\pi(r a)^{2}$ & Equation $(1)$ \\
2 & Receiver area $(A r)$ & $\pi(r r)^{2}$ & Equation $(2)$ \\
3 & Focal length $(F)$ & $(r a)^{2} / 4 \mathrm{~h}$ & Equation $(3)$ \\
4 & Rim angle $(Q)$ & $\tan (\mathrm{Q})=(1 /((d / 8 \mathrm{~h})-(2 \mathrm{~h} / \mathrm{d})))$ & Equation $(4)$ \\
5 & The surface area of the paraboloid $(A s)$ & $\left(8 \pi(f)^{2} / 3\right) *\left(((d / 4 f)+1)^{3 / 2}-1\right)$ & Equation $(5)$ \\
6 & Length of the circumference $(L)$ & $\pi * D a$ & Equation $(6)$ \\
7 & Concentration ratio $(C)$ & $A a / A r$ & Equation $(7)$ \\
\hline
\end{tabular}

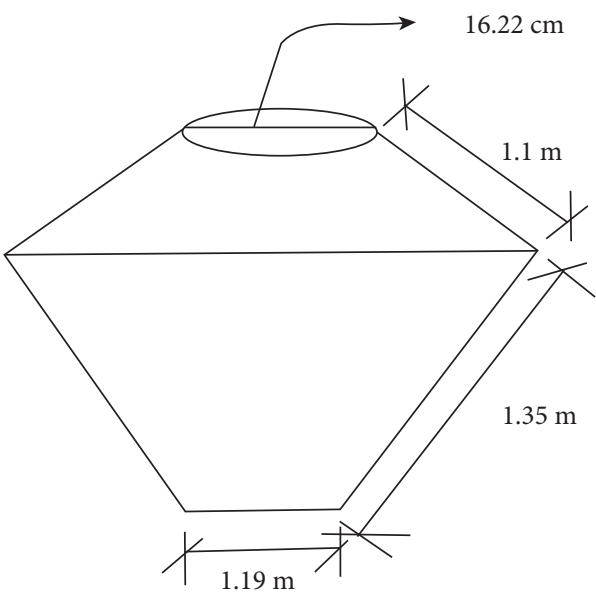

(a)

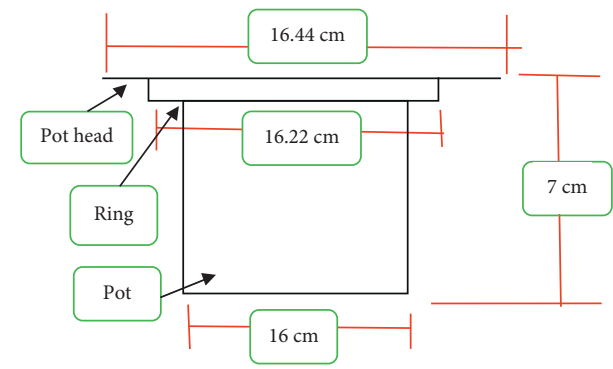

(b)

Figure 4: The dimension of the steel support (stand) of the cooker (a) and the dimension of the pot with receiver ring (b).

of a family, which has five members, was taken per some specified period.

\section{Results and Discussion}

4.1. Design of the Constructed Parabolic Solar Cooker. Table 5 summarizes the design results of the constructed parabolic solar cooker, which is designed based on the formulas listed in Table 1.
4.2. Performance of Parabolic Solar Cooker. The output energy, average solar radiation, input energy, efficiency, and power of the cooker were calculated based on equations (1)-(5) and are presented in Table 6.

The incoming solar radiation was concentrated on the focal point, which is located on the receiver, using the concentrator (parabolic dish). At a time of the day, which has high solar radiation, a high amount of solar radiation will be concentrated on the receiver, which leads to the presence 

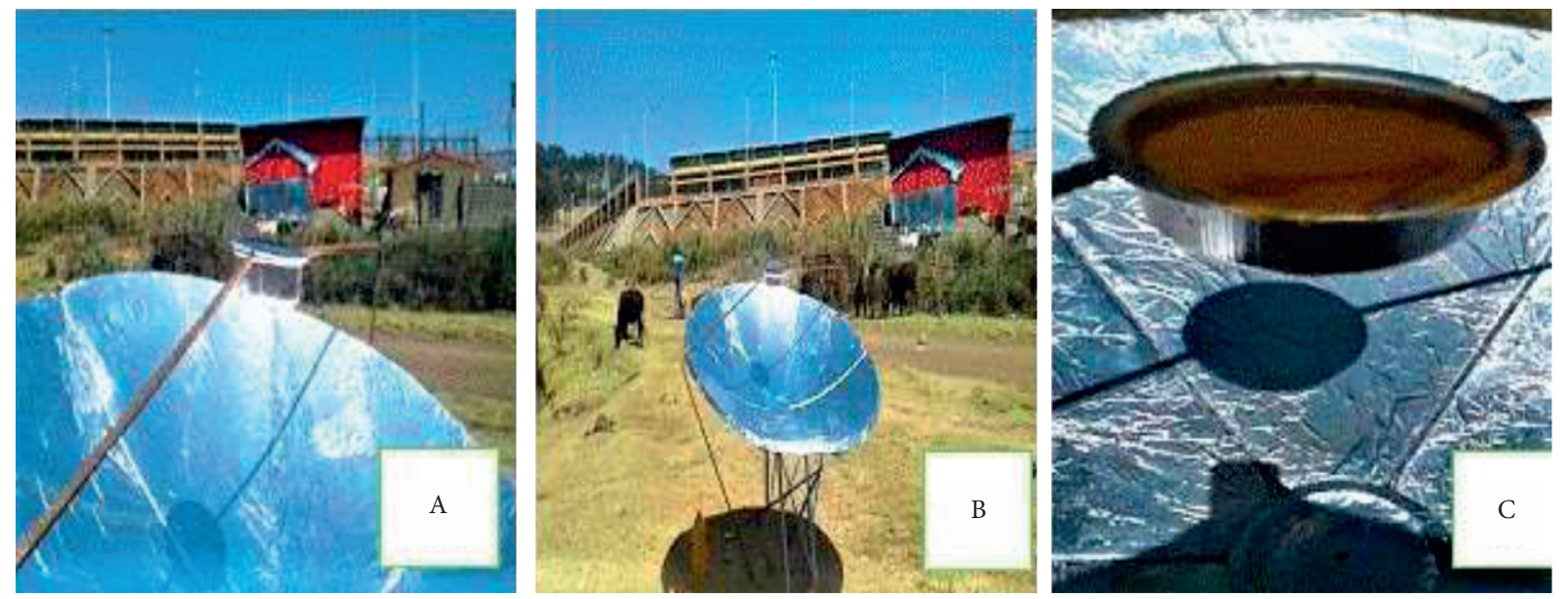

Figure 5: The concentrator of the parabolic solar cooker (a), the cooker with its steel support (stand) (b), and the black-painted pot placed on the receiver (c).

TABle 2: Metrological data of the experimental site during the experiment (boiling $1 \mathrm{~L}$ water).

\begin{tabular}{lcccccc}
\hline No. & Date & Time & Wind direction & Wind speed $(\mathrm{m} / \mathrm{s})$ & Solar radiation $\left(\mathrm{W} / \mathrm{m}^{2}\right)$ & Temperature $\left({ }^{\circ} \mathrm{C}\right)$ \\
\hline 1 & April 1, 2020 & $12: 30$ p.m. & 147.54 & 7.844 & 683.2 & 23.94 \\
2 & April 1, 2020 & $12: 45$ p.m. & 147.52 & 8.242 & 706.74 & 24.06 \\
3 & April 1, 2020 & $1: 00$ p.m. & 109.74 & 7.128 & 606.06 & 24.06 \\
4 & April 1, 2020 & $1: 15$ p.m. & 146.38 & 7.852 & 664.6 & 24.34 \\
\hline
\end{tabular}

TABle 3: Fuels that were used to be compared with the constructed parabolic solar cooker.

\begin{tabular}{lcr}
\hline No. & Fuels & Unit price (ETB) \\
\hline 1 & Kerosene (L) & 20 \\
2 & Charcoal (kg) & 10 \\
3 & Firewood (kg) & 20 \\
4 & Electricity (kWh) & 0.09 \\
\hline
\end{tabular}

ETB: Ethiopian birr.

TABLE 4: Quantity and time interval of foods that are cooked by parabolic solar cooker.

\begin{tabular}{|c|c|c|c|c|c|}
\hline No. & Experiment day & Cooked food & Cooking time interval & Quantity & $\begin{array}{l}\text { Consumption of food } \\
\text { for one family }\end{array}$ \\
\hline 1 & December 16, 2020 & Water & 12:00 p.m. $-12: 12$ p.m. & $1 \mathrm{~L}$ water & $15 \mathrm{~L} /$ day \\
\hline 2 & December 16, 2020 & Egg & 1:15 p.m.-2:15 p.m. & 2 eggs $+1 \mathrm{~L}$ water & 10 eggs/day \\
\hline 3 & December 16, 2020 & Potato & 2:20 p.m. $-4: 00$ p.m. & 2 potatoes $+1 \mathrm{~L}$ water & 10 potatoes/day \\
\hline 4 & December 30, 2020 & Nefro & 10:45 a.m. $-12: 25$ p.m. & Wheat $(150 \mathrm{~g})+$ been $(200 \mathrm{~g})+1 \mathrm{~L}$ water & 4 times/day \\
\hline 5 & December 30,2020 & Shero wet & $12: 37$ p.m. $-12: 55$ p.m. & Flour pea ( 9 soup spoons) $+1 \mathrm{~L}$ water & 2 times/day \\
\hline 6 & March 31, 2021 & Siga wet & 10:50 a.m.-1:00 p.m. & Meat $(0.25 \mathrm{~kg})+1 \mathrm{~L}$ water & 2 times/day \\
\hline 7 & March 31, 2021 & Rice & 1:52 p.m.-2:35 p.m. & Rice $(300 \mathrm{~g})+0.5 \mathrm{~L}$ water & 1 time/day \\
\hline
\end{tabular}

TABLE 5: Design parameters of the constructed parabolic solar cooker.

\begin{tabular}{lcc}
\hline No. & Parameter & Results \\
\hline 1 & Aperture diameter $(D a)$ & $1.8 \mathrm{~m}^{2}$ \\
2 & Aperture area $(A a)$ & $2.54 \mathrm{~m}^{2}$ \\
3 & Receiver diameter $(D r)$ & $0.16 \mathrm{~m}^{2}$ \\
4 & Receiver area $(A r)$ & $0.02 \mathrm{~m}^{2}$ \\
5 & Depth of the parabola $(d)$ & $0.30 \mathrm{~m}$ \\
6 & Focal length $(f)$ & $0.67 \mathrm{~m}$ \\
7 & Rim angle $(Q)$ & $67.38^{\circ}$ \\
8 & Circumference of the circle $(C)$ & $5.76 \mathrm{~m}^{\circ}$ \\
9 & The surface area of the paraboloid $(A s)$ & $2.81 \mathrm{~m}^{2}$ \\
10 & Length of the circumference $(L)$ & $5.76 \mathrm{~m}$ \\
11 & Concentration ratio $(C)$ & 123.46 \\
\hline
\end{tabular}


TABle 6: Performance of parabolic solar cooker.

\begin{tabular}{lcc}
\hline No. & Performance parameters & Result \\
\hline 1 & Output energy & $0.182 \mathrm{~kW}$ \\
2 & Average upcoming solar radiation & $0.665 \mathrm{~kW} / \mathrm{m}^{2}$ \\
3 & Input energy & $1.691 \mathrm{~kW}$ \\
4 & Efficiency & $10.75 \%$ \\
5 & Power & $0.3 \mathrm{~kW} / \mathrm{hr}$. \\
\hline
\end{tabular}

of high temperature. The black-painted pot, which is placed on the receiver, will absorb the heat and be used to cook different foods and boil water. In this study, the efficiency of the constructed parabolic solar cooker was $10.75 \%$. However, better efficiency of $37.75 \%$ and $26.6 \%$ was achieved by $[57,58]$, respectively.

Many factors could reduce the efficiency of the cooker. Some of the factors are temperature, wind, cloud, day of the year, time of the day, and type of reflective material. Profile deformation, structural torsion, and local irregularities can also affect the efficiency of a parabolic solar cooker [59]. The reflective material that is used in this cooker was aluminum foil. Aluminum foil is a good reflector, but after some time, it will crack. In addition, it will not be placed smoothly on the dish. This causes the rays not to concentrate on a receiver, which in turn reduce the efficiency of the cooker.

4.3. Comparison of Parabolic Solar Cooker with Other Fuels in terms of Cooking Time and Cost. The constructed parabolic solar cooker was compared with charcoal, firewood, kerosene, and electricity in terms of cooking time and cost. Figure 6 shows the cooking time of different foods using the constructed parabolic solar cooker, charcoal, kerosene, firewood, and electricity.

To compare parabolic solar cookers with other fuels, water and different foods are used, whose composition is described in Table 4 . In boiling water to $88^{\circ} \mathrm{C}$, the parabolic solar cooker took twelve minutes, but charcoal, kerosene, electricity, and firewood took eleven, thirteen, sixteen, and ten minutes, respectively. Except for firewood, a parabolic solar cooker boiled the water faster than the other fuels. In cooking an egg, a parabolic solar cooker took sixty minutes, but charcoal, kerosene, electricity, and firewood took thirty, twenty-nine, twenty-eight, and twenty-six minutes, respectively. Firewood can cook an egg faster than both parabolic solar cookers and the other fuels. In cooking potato, parabolic solar cooker took hundred minutes, but charcoal, kerosene, electricity, and firewood took fortythree, thirteen, fourteen, and fifteen minutes, respectively. Kerosene can cook potatoes faster than both parabolic solar cookers and the other fuels.

In cooking Nefro, parabolic solar cooker took forty minutes, but charcoal, kerosene, electricity, and firewood took one hundred thirty-five, ninety, ninety-one, and sixty-three minutes, respectively. The parabolic solar cooker can cook Nefro faster than the other fuels. In cooking Shero wet, parabolic solar cooker took eighteen minutes, but charcoal, kerosene, electricity, and firewood took seventy-nine, sixtysix, sixty-eight, and sixty minutes, respectively. Except for

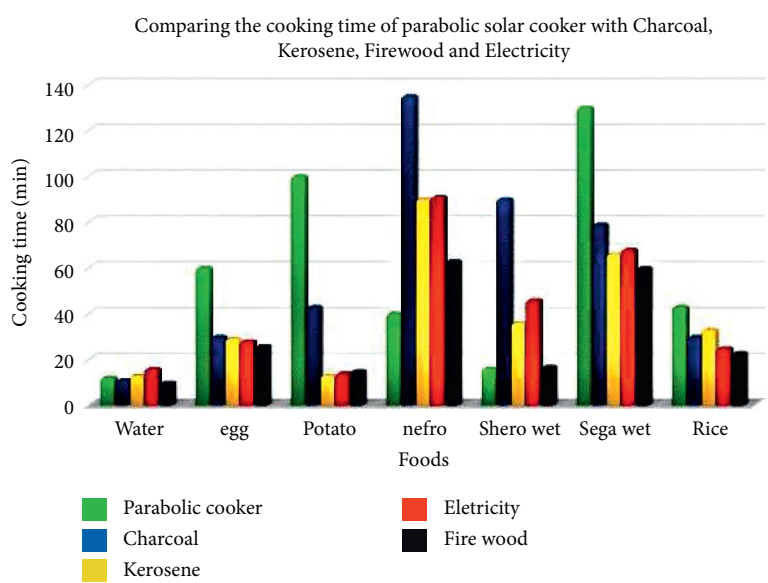

Figure 6: Comparison of parabolic solar cooker with other fuels in terms of cooking time.

firewood, a parabolic solar cooker can cook Shero wet faster than the other fuels. In cooking Siga wet, parabolic solar cooker took one hundred thirty minutes, but charcoal, kerosene, electricity, and firewood took seventy-nine, sixty-six, sixty-eight, and sixty minutes, respectively. Firewood can cook Siga wet faster than both parabolic solar cooker and the other fuels. In cooking rice, a parabolic solar cooker took forty-three minutes, but charcoal, kerosene, electricity, and firewood took thirty, thirty-three, twenty-five, and twentythree minutes, respectively. Firewood can cook potatoes faster than both parabolic solar cookers and the other fuels. Parabolic solar cooker cooks Nefro and Shero wet faster than any other fuels. The reason for this is the fact that these foods were cooked around noon. It is well known that there is a high amount of solar radiation at noon period. If there is a high amount of solar radiation, the cooking time will be small.

Generally, even though the parabolic solar cooker took a longer time to cook an egg, rice, potato, and Siga wet than the other fuels, it cooks Nefro faster than the other fuels. It is also the second-fastest cooker in cooking Shero wet compared to the other fuels. Nefro and Shero wet were cooked around solar noon, where the solar intensity becomes highest.

Table 7 shows the energy cost of different fuels to boil oneliter water and to cook one egg, potato, Nefro, Shero wet, Siga $w e t$, and rice. These foods were also cooked by the parabolic solar cooker. The energy cost of these fuels is calculated by considering the amount of fuel used to cook the given foods with a unit cost of the fuel, which is described in Table 3.

As shown in Table 4, a family requires Shero wet 2 times per day, Nefro 4 times per day, 15 L water, 10 eggs, 10 potatoes, Siga wet 2 times per day, and rice 1 time per day . Figure 7 shows the energy cost of different fuels in boiling water and cooking different foods for a single family.

To boil $15 \mathrm{~L}$ water/day using charcoal, firewood, kerosene, and electricity, $2.5 \mathrm{ETB} /$ day, $24 \mathrm{ETB} /$ day, $15 \mathrm{ETB} /$ day, and $0.36 \mathrm{ETB} /$ day are required, respectively. To cook 10 eggs/day using charcoal, firewood, kerosene, and electricity, $12.5 \mathrm{ETB} /$ day, $32 \mathrm{ETB} /$ day, $5 \mathrm{ETB} /$ day, and $0.42 \mathrm{ETB} /$ day are required, respectively. To cook 10 potatoes/day using charcoal, firewood, kerosene, and electricity, $12.5 \mathrm{ETB} /$ day, $16 \mathrm{ETB} /$ day, $10 \mathrm{ETB} /$ day, and $0.21 \mathrm{ETB} /$ day are required, 
TABLE 7: Amount of fuel used in boiling water and cooking foods for a single person.

\begin{tabular}{|c|c|c|c|c|c|c|c|c|c|}
\hline \multirow[b]{2}{*}{ No. } & \multirow[b]{2}{*}{ Foods } & \multicolumn{2}{|c|}{ Charcoal } & \multicolumn{2}{|c|}{ Firewood } & \multicolumn{2}{|c|}{ Kerosene } & \multicolumn{2}{|c|}{ Electricity } \\
\hline & & $\begin{array}{c}\text { Amount } \\
(\mathrm{kg})\end{array}$ & $\begin{array}{c}\text { Energy cost } \\
\text { (ETB) }\end{array}$ & $\underset{(\mathrm{kg})}{\operatorname{Amount}}$ & $\begin{array}{c}\text { Energy cost } \\
\text { (ETB) }\end{array}$ & $\begin{array}{c}\text { Amount } \\
\text { (L) }\end{array}$ & $\begin{array}{c}\text { Energy cost } \\
\text { (ETB) }\end{array}$ & $\begin{array}{c}\text { Amount } \\
(\mathrm{kWh})\end{array}$ & $\begin{array}{c}\text { Energy cost } \\
\text { (ETB) }\end{array}$ \\
\hline 1 & Water & 0.025 & 2.50 & 0.08 & 1.6 & 0.05 & 1 & 0.267 & 0.024 \\
\hline 2 & Egg & 0.025 & 2.50 & 0.16 & 3.2 & 0.025 & 0.5 & 0.467 & 0.042 \\
\hline 3 & Potato & 0.025 & 2.50 & 0.08 & 1.6 & 0.05 & 1 & 0.234 & 0.021 \\
\hline 4 & Nefro & 0.075 & 7.5 & 0.75 & 15 & 0.5 & 10 & 1.517 & 0.137 \\
\hline 5 & $\begin{array}{c}\text { Shero } \\
\text { wet }\end{array}$ & 1 & 10.00 & 0.5 & 10 & 0.4 & 8 & 0.767 & 0.069 \\
\hline 6 & Siga wet & 1 & 10.00 & 0.75 & 15 & 0.5 & 10 & 1.134 & 0.102 \\
\hline 7 & Rice & 0.025 & 2.50 & 0.16 & 3.2 & 0.025 & 0.5 & 0.417 & 0.038 \\
\hline
\end{tabular}

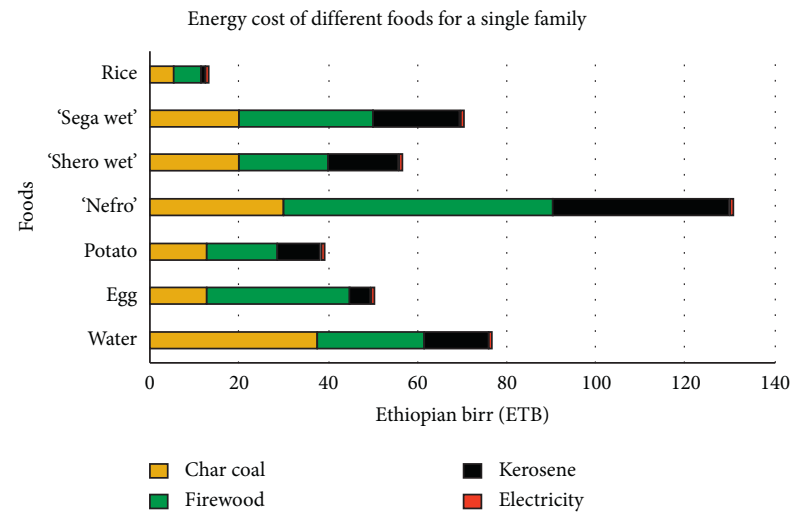

Figure 7: Energy cost of different fuels that are used in boiling water and cooking foods for a single family.

respectively. To cook 1 Nefro/day using charcoal, firewood, kerosene, and electricity, $30 \mathrm{ETB} /$ day, $60 \mathrm{ETB} /$ day, $40 \mathrm{ETB} /$ day, and $0.55 \mathrm{ETB} /$ day are required, respectively. To cook 2 Shero wet/day using charcoal, firewood, kerosene, and electricity, $20 \mathrm{ETB} /$ day, $30 \mathrm{ETB} /$ day, $16 \mathrm{ETB} /$ day, and 0.14 $\mathrm{ETB} /$ day are required, respectively. To cook 10 Siga wet/day using charcoal, firewood, kerosene, and electricity, 2.5 ETB/ day, $30 \mathrm{ETB} /$ day, $20 \mathrm{ETB} /$ day, and $0.20 \mathrm{ETB} /$ day are required, respectively. To cook 1 rice/day using charcoal, firewood, kerosene, and electricity, $5 \mathrm{ETB} /$ day, $6.4 \mathrm{ETB} /$ day, $1 \mathrm{ETB} /$ day, and $0.07 \mathrm{ETB} /$ day are required, respectively. Solar energy is free energy [60]. Therefore, solar cookers in general, parabolic solar cooker, in particular, do not have an energy cost. Therefore, it is preferable technology for developing countries including Ethiopia.

\section{Conclusion}

A dual-axis sun-tracking solar cooker was designed and constructed using locally available materials. The design parameters were aperture area, receiver area, focal length, rim angle, the surface area of the paraboloid, length of the circumference, and concentration ratio. Its performance was also investigated by calculating its efficiency and comparing it with charcoal, firewood, kerosene, and electricity in terms of cooking time and energy cost of cooking. The average solar radiation reaching the earth's surface on the day of the experiment was $0.665 \mathrm{~kW} / \mathrm{m}^{2}$. The output energy, input energy, efficiency, and power of constructed parabolic solar cooker were $0.182 \mathrm{~kW}, 1.691 \mathrm{~kW}, 10.75 \%$, and $0.3 \mathrm{~kW} / \mathrm{hr}$, respectively. The constructed parabolic solar cooker showed the best performance in cooking Nefro and Shero wet at a short time compared to the other fuels. The parabolic solar cooker showed a good performance in boiling water for a short time next to firewood and charcoal. However, the parabolic solar cooker took a relatively long time in cooking egg, potato, and Siga wet. One of the main reasons for the slow cooking time might be due to the cracking of the reflective material (aluminum foil), which is also responsible for the reduction of the efficiency of the cooker. Since the parabolic solar cooker does not have any energy cost, it can save the energy cost of cooking foods.

\section{Recommendation}

The reflective material that was used in this experiment was aluminum foil. This material cracks and shrinks after some time, which leads to the reduction of efficiency of the cooker. Therefore, further investigation should be conducted to replace aluminum foil with a reflective material that is strong and durable to improve the efficiency of the cooker. Generally, due to its cost and time effectiveness, a parabolic solar cooker will be a very good technology especially for developing countries including Ethiopia.

\section{Data Availability}

All data are available within this article.

\section{Conflicts of Interest}

The authors declare that they have no conflicts of interest.

\section{Acknowledgments}

This work was sponsored by Addis Ababa Science and Technology University.

\section{References}

[1] M. Lenzen, M. Lenzen, M. Wier et al., "A comparative multivariate analysis of household energy requirements in Australia, Brazil, Denmark, India and Japan," Energy, vol. 31, no. 2-3, pp. 181-207, 2006. 
[2] R. M. Muthusivagami, R. Velraj, and R. Sethumadhavan, "Solar cookers with and without thermal storage-a review," Renewable and Sustainable Energy Reviews, vol. 14, no. 2, pp. 691-701, 2010.

[3] A. Carlsson-Kanyama and K. Boström-Carlsson, "Energy use for cooking and other stages in the life cycle of food: a study of wheat, spaghetti, pasta, barley, rice, potatoes, couscous and mashed potatoes," Stockholms Universitet/Systemekologiochfoi, vol. 160, 2001.

[4] M. Shahbaz, A. R. Chaudhary, and I. Ozturk, "Does urbanization cause increasing energy demand in Pakistan? empirical evidence from STIRPAT model," Energy, vol. 122, pp. 83-93, 2017.

[5] J. Okino, A. J. Komakech, J. Wanyama, H. Ssegane, E. Olomo, and T. Omara, "Performance characteristics of a cooking stove improved with sawdust as an insulation material," Journal of Renewable Energy, vol. 2021, Article ID 9969806, 12 pages, 2021.

[6] A. Katiyar and C. Pandey, "A review of solar radiation models-part I," Journal of Renewable Energy, vol. 2013, Article ID 168048, 11 pages, 2013.

[7] A. M. Omer, "Energy, environment and sustainable development," Renewable and Sustainable Energy Reviews, vol. 12, no. 9, pp. 2265-2300, 2008.

[8] A. P. Aizebeokhai, "Global warming and climate change: realities, uncertainties and measures," International Journal of Physical Sciences, vol. 4, no. 13, pp. 868-879, 2009.

[9] M. Makenzi, J. Muguthu, and E. Murimi, "Maximization of site-specific solar photovoltaic energy generation through tilt angle and sun-hours optimization," Journal of Renewable Energy, vol. 2020, Article ID 8893891, 11 pages, 2020.

[10] S. Fahad and J. Wang, "Farmers' risk perception, vulnerability, and adaptation to climate change in rural Pakistan," Land Use Policy, vol. 79, pp. 301-309, 2018.

[11] V. Ramanathan, "Climate change, air pollution, and health: common sources, similar impacts, and common solutions," in Health of People, Health of Planet and Our Responsibility: Climate Change, Air Pollution and Health, W. K. Al-Delaimy, V. Ramanathan, and M. Sánchez Sorondo, Eds., Springer International Publishing, Cham, Germany, pp. 49-59, 2020.

[12] S. Shafiee and E. Topal, "A long-term view of worldwide fossil fuel prices,” Applied Energy, vol. 87, no. 3, pp. 988-1000, 2010.

[13] M. Hafner and S. Tagliapietra, The Geopolitics of the Global Energy Transition, Springer Nature, Basingstoke, UK, 2020.

[14] Q. Abbas, A. R. Khan, A. Bashir et al., "Scaling up renewable energy in Africa: measuring wind energy through econometric approach," Environmental Science and Pollution Research, vol. 27, no. 29, pp. 36282-36294, 2020.

[15] C. Thirugnanam, S. Karthikeyan, and K. Kalaimurugan, "Study of phase change materials and its application in solar cooker," Materials Today: Proceedings, vol. 33, pp. 2890-2896, 2020.

[16] N. Nayak, H. Abu Jarir, and H. Al Ghassani, "Solar cooker study under Oman conditions for late evening cooking using stearic acid and acetanilide as PCM materials," Journal of Solar Energy Engineering, vol. 2016, Article ID 2305875, 6 pages, 2016.

[17] E. Calabrò, "An algorithm to determine the optimum tilt angle of a solar panel from global horizontal solar radiation," Journal of Renewable Energy, vol. 2013, Article ID 307547, 12 pages, 2013.

[18] Z. H. Hulio, "Assessment of wind characteristics and wind power potential of gharo, Pakistan," Journal of Renewable Energy, vol. 2021, Article ID 8960190, 17 pages, 2021.
[19] E. A. Lawin, S. D. Bazyomo, and A. Ouedraogo, "Solar photovoltaic energy and electricity security on ECOWAS countries," Journal of Renewable Energy, vol. 2017, Article ID 7142350, 9 pages, 2017.

[20] T.-T. Nguyen and T. Boström, "Multiobjective optimization of a hybrid wind/solar battery energy system in the arctic," Journal of Renewable Energy, vol. 2021, Article ID 8829561, 11 pages, 2021.

[21] M. Hafner, S. Tagliapietra, and L. De Strasser, Energy in Africa: Challenges and Opportunities, Springer Nature, Basingstoke, UK, 2018.

[22] S. Z. Farooqui, "Determination of performance measuring parameters of an improved dual paraboloid solar cooker," International Journal of Photoenergy, vol. 2017, Article ID 9459531, 12 pages, 2017.

[23] F. Cao, L. Wang, and T. Zhu, "Design and optimization of elliptical cavity tube receivers in the parabolic trough solar collector," International Journal of Photoenergy, vol. 2017, Article ID 1471594, 7 pages, 2017.

[24] R. A. Ferdaus, M. A. Mohammed, S. Rahman, S. Salehin, and M. A. Mannan, "Energy efficient hybrid dual axis solar tracking system," Journal of Renewable Energy, vol. 2014, Article ID 629717, 12 pages, 2014.

[25] A. Amoah, E. Kwablah, K. Korle, and D. Offei, "Renewable energy consumption in Africa: the role of economic wellbeing and economic freedom," Energy, Sustainability and Society, vol. 10, no. 1, p. 32, 2020.

[26] P. J. Asilevi, E. Quansah, L. K. Amekudzi, T. Annor, and N. A. B. Klutse, "Modeling the spatial distribution of global solar radiation (GSR) over Ghana using the Ångström-Prescott sunshine duration model," Scientific African, vol. 4, Article ID e00094, 2019.

[27] W. Sawadogo, M. S. Reboita, A. Faye et al., "Current and future potential of solar and wind energy over Africa using the RegCM4 CORDEX-CORE ensemble," Climate Dynamics, vol. 57, pp. 1-26, 2020.

[28] J. F. Griffiths, "Africa, climate of," in Climatology, pp. 6-16, Springer, Boston, MA, USA, 1987.

[29] E. E. S. Michaelides, Alternative Energy Sources, Springer Science \& Business Media, Berlin, Germany, 2012.

[30] S. Khadem, S. Ullah, S. Aditya, H. Ghosh, and L. Mariam, Solar and Wind Energy Resource Assessment (SWERA), Renewable Energy Research Center, University of Dhaka, Dhaka, Bangladesh, 2009.

[31] D. A. F. Meujo and M. T. Hamann, "Science, policy, and risk management: case of seafood safety," in Environmental Toxicology, pp. 461-501, Springer, Berlin, Germany, 2013.

[32] N. S. Ouedraogo, "Africa energy future: alternative scenarios and their implications for sustainable development strategies," Energy Policy, vol. 106, pp. 457-471, 2017.

[33] P. G. Munro, S. Samarakoon, and G. A. van der Horst, "African energy poverty: a moving target," Environmental Research Letters, vol. 15, no. 10, Article ID 104059, 2020.

[34] M. L. Benka-Coker, W. Tadele, A. Milano, D. Getaneh, and H. Stokes, "A case study of the ethanol cleancook stove intervention and potential scale-up in Ethiopia," Energy for Sustainable Development, vol. 46, pp. 53-64, 2018.

[35] R. P. Overend, "Biomass energy heat provision for cooking and heating in developing countries," in Encyclopedia of Sustainability Science and Technology, R. A. Meyers, Ed., Springer, New York, NY, USA, 2017.

[36] S. L. Hemstock, M. Charlesworth, and R. D. Singh, "Household energy usage, indoor air pollution, and health," in Good Health and Well-Being, W. Leal Filho, T. Wall, 
A. M. Azul, L. Brandli, and P. G. Özuyar, Eds., Springer International Publishing, Cham, Germany, pp. 382-394, 2020.

[37] S. F. Martin and J. Tirman, Women, Migration, and Conflict: Breaking a Deadly Cycle, Springer, Berlin, Germany, 2009.

[38] C. Winder, "Carbon monoxide-induced death and toxicity from charcoal briquettes," Medical Journal of Australia, vol. 197, no. 6, pp. 349-350, 2012.

[39] J. Pechstein and M. Kaltschmitt, "Liquid hydrocarbon fuels derived from alcohols," in Encyclopedia of Sustainability Science and Technology Series, M. Kaltschmitt, Ed., pp. 1023-1046, Springer, New York, NY, USA, Second edition, 2019.

[40] S. Pront-van Bommel, "A reasonable price for electricity," Journal of Consumer Policy, vol. 39, no. 2, pp. 141-158, 2016.

[41] B. C. Anilkumar, R. Maniyeri, and S. Anish, "Design, fabrication and performance assessment of a solar cooker with optimum composition of heat storage materials," Environmental Science and Pollution Research International, vol. 27, pp. 1-9, 2020.

[42] Y. Alila, P. Kuras, M. Schnorbus, and R. O. Hudson, "Forests and floods: a new paradigm sheds light on age-old controversies," Water Resources Research, vol. 45, no. 8, 2009.

[43] F. Riva, M. V. Rocco, F. Gardumi, G. Bonamini, and E. Colombo, "Design and performance evaluation of solar cookers for developing countries: the case of Mutoyi, Burundi," International Journal of Energy Research, vol. 41, no. 14, pp. 2206-2220, 2017.

[44] H. Sawarn, S. K. Shukla, and P. K. S. Rathore, “Development in solar cooking technology in the last decade: a comprehensive review," in Proceedings of the IOP Conference Series: Materials Science and Engineering, February 2021.

[45] E. Butler, Y.-T. Hung, M. Suleiman Al Ahmad, R. Y.-L. Yeh, R. L.-H. Liu, and Y.-P. Fu, "Oxidation pond for municipal wastewater treatment," Applied Water Science, vol. 7, no. 1, pp. 31-51, 2017.

[46] M. S. Al-Soud, E. Abdallah, A. Akayleh, S. Abdallah, and E. S. Hrayshat, "A parabolic solar cooker with automatic two axes sun tracking system," Applied Energy, vol. 87, no. 2, pp. 463-470, 2010.

[47] N. Mbodji and A. Hajji, "Performance testing of a parabolic solar concentrator for solar cooking," Journal of Solar Energy Engineering, vol. 138, no. 4, 2016.

[48] A. G. Bhave and C. K. Kale, "Development of a thermal storage type solar cooker for high temperature cooking using solar salt," Solar Energy Materials and Solar Cells, vol. 208, Article ID 110394, 2020.

[49] A. A. M. Omara, A. A. A. Abuelnuor, H. A. Mohammed, D. Habibi, and O. Younis, "Improving solar cooker performance using phase change materials: a comprehensive review," Solar Energy, vol. 207, pp. 539-563, 2020.

[50] J. M. Arenas, "Design, development and testing of a portable parabolic solar kitchen," Renewable Energy, vol. 32, no. 2, pp. 257-266, 2007.

[51] Y. R. Suple and S. Thombre, "Performance evaluation of parabolic solar disc for indoor cooking," IOSR Journal of Mechanical and Civil Engineering, vol. 4, no. 6, pp. 42-47, 2013.

[52] H.-G. Lee and S. S. Rao, "Uncertain analysis of a stationary solar compound parabolic concentrator PV collector system using fuzzy set theory," Journal of Renewable Energy, vol. 2018, Article ID 2915731, 12 pages, 2018.

[53] S. M. M. Ahmed, M. R. Al-Amin, S. Ahammed, F. Ahmed, A. M. Saleque, and M. Abdur Rahman, "Design, construction and testing of parabolic solar cooker for rural households and refugee camp," Solar Energy, vol. 205, pp. 230-240, 2020.

[54] Z. Rongrong, Y. Yongping, Y. Qin, and Z. Yong, "Modeling and characteristic analysis of a solar parabolic trough system: thermal oil as the heat transfer fluid," Journal of Renewable Energy, vol. 2013, Article ID 389514, 8 pages, 2013.

[55] D. K. Kedida, D. A. Amibe, and Y. T. Birhane, "Performance of a pebble bed thermal storage integrated with concentrating parabolic solar collector for cooking," Journal of Renewable Energy, vol. 2019, Article ID 4238549, 12 pages, 2019.

[56] B. A. Mekonnen, K. W. Liyew, and M. T. Tigabu, "Solar cooking in Ethiopia: experimental testing and performance evaluation of SK14 solar cooker," Case Studies in Thermal Engineering, vol. 22, Article ID 100766, 2020.

[57] M. S. Khan, M. Abid, K. P. Amber, H. M. Ali, M. Yan, and S. Javed, "Numerical performance investigation of parabolic dish solar-assisted cogeneration plant using different heat transfer fluids," International Journal of Photoenergy, vol. 2021, Article ID 5512679, 15 pages, 2021.

[58] R. Chaudhary and A. Yadav, "Experimental investigation of solar cooking system based on evacuated tube solar collector for the preparation of concentrated sugarcane juice used in jaggery making," Environment, Development and Sustainability, vol. 5, pp. 1-17, 2020.

[59] F. Francini, D. Fontani, P. Sansoni, L. Mercatelli, D. Jafrancesco, and E. Sani, "Evaluation of surface slope irregularity in linear parabolic solar collectors," International Journal of Photoenergy, vol. 2012, Article ID 921780, 6 pages, 2012.

[60] J. T. Liu, M. Li, Q. F. Yu, and D. L. Ling, "A novel parabolic trough concentrating solar heating for cut tobacco drying system," International Journal of Photoenergy, vol. 201410 pages, Article ID 209028, 2014. 